\title{
Who gets left main stent in a hospital that routinely treats left main disease with coronary artery bypass graft surgery?
}

\section{Lovel Giunio*, \\ Anteo Bradarić, \\ Jakša Zanchi, \\ Mislav Lozo, \\ Dino Mirić, \\ Lada Giunio}

University of Split School of Medicine, University Hospital Centre Split, Split, Croatia
KEYWORDS: percutaneous coronary intervention, left main coronary disease, stent, surgical revascularization, Syntax score.

CITATION: Cardiol Croat. 2018;13(1-2):39. I https://doi.org/10.15836/ccar2018.39

*ADDRESS FOR CORRESPONDENCE: Lovel Giunio, Klinički bolnički centar Split, Šoltanska 1, HR-21000 Split, Croatia. / Phone: +385-99-2039-999 / E-mail: lovelgiunio@hotmail.com

ORCID: Lovel Giunio, https://orcid.org/0000-0002-1268-5698 • Anteo Bradarić, https://orcid.org/0000-0002-9843-6309 Jakša Zanchi, https://orcid.org/0000-0003-2700-2121 • Mislav Lozo, https://orcid.org/0000-0001-7530-4760 Dino Mirić, https://orcid.org/0000-0002-4487-1372 • Lada Giunio, https://orcid.org/0000-0001-8052-6413

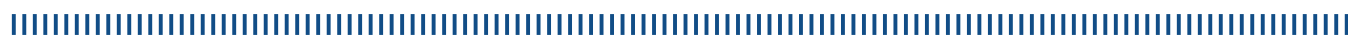

Aims: What are clinical, angiographic and procedural characteristics of the interventionally treated patients with left main coronary artery disease in the hospital that does not routinely use percutaneous coronary intervention (PCI) for left main disease ${ }^{1,2}$, and how do they fare?

Patients and Methods: All patients treated with PCI for left main coronary artery disease between January 2007 and 2017 were enrolled. The group consisted of patients who refused coronary artery bypass graft (CABG) surgery, were refused by surgeons or severity of their clinical condition did not allow transfer to cardiac surgery.

Results: Out of 525 (6.3\%) patients with left main disease 467 (88.9\%) were treated surgically. Fifty-eight (11.1\%) patients were treated with PCI. Mean age of patients was $66.9 \pm 11.9$ years, and $48(82.7 \%)$ were male. The mean SYNTAX score was $25.6 \pm 8.8$ and logistic Euro SCORE was $14.95 \%$. Fifteen patients (25.9\%) had unstable angina pectoris, 28 (48.2\%) had non-ST-segment elevation myocardial infarction and 15 (25.9\%) had ST-segment elevation myocardial infarction. Twelve (20.7\%) patients were obese (body mass index >30), 7 (12\%) had diabetes, 39 (67.2\%) had arterial hypertension, 12 (20.7\%) had hypercholesterolemia and 28 (48.3\%) were smokers. Thirty (51.7\%) patients have already had a myocardial infarction and 16 (27.6\%) have already had CABG. Right transradial approach was used in 25 (43.1\%) cases, right transfemoral in 26 (44.8\%), left transradial in 5 (8.6\%) and left transfemoral in 2 (3.5\%) cases. In $52(89.6 \%)$ patients $6 \mathrm{~F}$ guiding catheter was used. Seven patients (12\%) had only isolated left main disease, 12 (20.7\%) had also accompanying single, 16 (27.6\%) double, and 23 (39.7\%) triple vessel disease. Nine (15.5\%) patients had occlusion, and 49 (84.5\%) had significant stenosis of left main. Only 5 (8.6\%) patients underwent balloon angioplasty alone and the rest were stented, nine (15.5\%) with bare-metal stents and $44(75.8 \%)$ drug-eluting stents. Average stent diameter was $3.86 \pm 0.69 \mathrm{~mm}$ and length was $18.5 \pm 6.45 \mathrm{~mm}$. Twenty nine (50\%) patients underwent additional intervention in another coronary artery during the same procedure. There was $4.9 \%$ procedural mortality, and in-hospital mortality was $9.8 \%$.

Conclusions: In a hospital that routinely uses CABG for left main disease, PCI has been demonstrated as an effective treatment when surgical treatment was not feasible or refused by the patient.

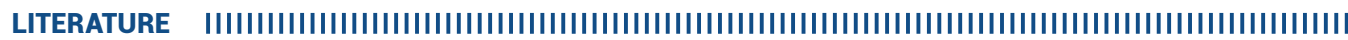

1. Gripenberg T, Jokhaji F, Östlund-Papadogeorgos N, Ekenbäck C, Linder R, Samad B, et al. Outcome and selection of revascularization strategy in left main coronary artery stenosis. Scand Cardiovasc J. 2018 Jan 22:1-8. https://doi.org/10.1080/14017431.2018.1429648

2. Zhang C, Zheng $Y$, Liu X, Cheng $Y$, Liu $Y$, Yao $Y$, et al. Identify Unsuitable Patients with Left Main Coronary Artery Disease in Intermediate SYNTAX Scores Treated by Percutaneous Coronary Intervention. Heart Surg Forum. 2017 Dec 21;20(6):E258-E262. https://doi.org/10.1532/hsf.1741 